\title{
Influence of surface treatments in natural fiber reinforced composites
}

\author{
M Aruna*, A A Sultan, M A A Al Shehhi \\ Al Ghurair University, Dubai, UAE
}

\begin{abstract}
There have been numerous endeavors to replace synthetic fibers with natural fibers in fiber-reinforced composites, due to increasing environmental alertness and diminution of oil assets. The information that natural fibers are existing inexpensively and in plenty, being biodegradable and low density, have driven many scientists throughout the world to reconnoiter their application potential in several industrial segments. Nevertheless, natural fibers also require some confines such as high moisture absorption and subsequent swelling and degradation, poor chemical and fire resistance, high dispersion of mechanical properties, poor interfacial interactions with polymeric matrices. Consequently, there is an enormous concern to modify the surface of natural fibers through many techniques, in order to overcome their intrinsic downsides and to effectively utilize these materials in different applications. The chemical treatment of fiber is intended at improving the adhesion between the fiber surface and the matrix. Modification in fiber surface results with increase in fiber strength. This study compares the result of different types of surface treatments of natural fibrous materials, chiefly Calotropis procera and Sisal fibers, on the mechanical properties of fiber composites. The application of surface treatments on fibrous materials can improve the compatibility with composite materials.
\end{abstract}

\section{INTRODUCTION}

The growing ecological and environmental consciousness has driven efforts for development of new innovative materials for various end-use applications. Polymers synthesized from natural resources, have gained considerable research interest in the recent years. Environmental and economic alarms are motivating research in the expansion of novel materials for buildings, furniture, packaging and automotive productions. Particularly attractive are the new materials derived from natural renewable resources which prevent further stress on the environment such as that caused by the depletion of already dwindling wood resources from forests.

The potential of use of natural fibers, especially as composite reinforcement, depends largely on the increasing of regulation and its commercial characteristics, namely by creating standards for their production and post-treatment. The evolution of the knowledge regarding natural fibers will allow standardizing the kind of fibers available in the market and allowing designers to have higher levels of trust concerning mechanical and chemical properties. The scientific community has a crucial role in relation to the releasing of accurate and fully characterized studies allowing a robust increase in fundamental knowledge about natural fibers.

${ }^{*}$ Corresponding Author: m.aruna@agu.ac.ae 
In the last few years, there has been a stringent consumer's awareness towards new products from renewable sources. Green marketing, new directives on recycling, social influence and change of cognitive values have led the consumer towards environmentally friendly products. In particular, composite materials are being developed and redesigned aiming to improve and to adapt traditional products and introduce new products in a sustainable and responsible way. Aerospace technology was the first sector to boast a significant range of applications for fiber-reinforced polymers (FRP). Since then, however, these construction materials have also been used for numerous technical applications, especially where high strength and stiffness at low weight is required. The good specific, i.e. weight-related properties, of these materials (unsaturated polyester, polyurethane, phenolic or epoxy resins) are due to the low densities of the applied matrix systems and the presence of embedded fibers (glass, aramid and carbon fibers) that give high strength and stiffness.

Calotropis gigantea (CG) fiber was identified and its physical, chemical, and mechanical properties of $\mathrm{CG}$ fibers were studied. The obtained values of various properties were comparable to the properties of other lignocellulosic fibers available in the literatures, confirming their potential as reinforcements in polymer matrix composites. This motivates to develop the CG fiber based polymer composites for various applications. In this context, the present work deals with the preparation and study of tensile, flexural, impact, hardness, and water absorption properties of CG fiber reinforced epoxy composites. Tensile strength, impact strength, density and hardness of hybrid Calotropis gigantea stem fiber reinforced composites are analyzed [1]. Results illustrates that the use of less than 12 gm glass fiber in this composite increases tensile strength, impact, density and hardness.

Sustainable development is progressively becoming a priority of governments and business sectors that is driven by growing environmental attentiveness. Much academic research explores new ways to create greener and environmentally friendlier materials for variety of applications ranging from aeronautic, automotive and construction industry. Natural fibers are renewable resources in many developing countries of the world. The awareness in natural fiber-reinforced composite materials is quickly increasing their industrial applications and major research $[2,3]$.

Calotropis gigentea is drought resistant; salt tolerant to a relatively high degree, grows wild up to 900 meters throughout the country [4] and prefers disturbed sandy soils with mean annual rainfall: $300-400 \mathrm{~mm}$. Calotropis bast fiber is one of these types that have been extracted manually up to now. Some research article investigates the effect of new decorticator machine on properties of extracted fiber and compared with separated fibers manually. The mentioned decorticator machine was able to extract bast fiber without shattering stems and flowing latex. Some studied properties were morphological characterization, tensile properties (tensile strength, Young's modulus and strain) and density of fiber. The results indicated that machinery extraction method had no significant effect on the fiber morphology [5].

Calotropis stem has valuable fibers with various applications in the industry. Since extraction found to be more complex, extraction machine with the capacity of $2 \mathrm{~kg} / \mathrm{h}$ based on dried mass of barks and fibers was developed [6]. Calotropis gigentea fruit fiber reinforced composites was prepared and mechanically tested. The tensile strength improved with upsurge in fiber content. Further, the wear behavior of the Calotropis gigentea fruit fiber composite were studied with increase in fiber content [7]. Several chemical modifications are employed to improve the interfacial matrix-fiber bonding resulting in the enhancement of mechanical properties of the composites. They determined the mechanical and machining characteristics of the Calotropis gigentea fruit fiber composites that are found good [8]. 
Study on the mechanical properties of Calotropis gigantean composites revealed very less than the flax fiber composites. The suitable coupling agent and its concentration can be used out to improve its mechanical properties [9]. The feasibility of applying two kinds of mudar (Calotropis gigantea) fibers, namely bark fibers and seed fibers, as an alternative raw material for fiber-reinforced composite (FRC) was investigated. The mechanical assets of the mudar bark fibers are tensile strength $381 \mathrm{MPa}$, strain at break 2.1\% and Young's modulus 9.7 GPa. In general, both types of fibers have enough potential for replacing other fibrous raw materials as reinforcing agent [10].

Sisal (Agave sisalana) is a plant that revenues stiff fibers conventionally castoff for rope and twine. It is habitually mined by a method recognized as decortications. Sisal is esteemed for cordage use for of its strength, durability, ability to stretch, affinity for positive dyestuffs, and confrontation to worsening in saltwater. Sisal is castoff by manufacturing in three ratings. The lower rating fiber is processed by the paper industry because of its high content of cellulose and hemicelluloses. The medium grade fiber is used in the cordage industry for making: ropes, baler and binders twine. Ropes and twines are widely employed for marine, agricultural, and general industrial use. The top-grade fiber after treatment is transformed into yarns and cast-off by the rug industry. Sisal is a renewable reserve par excellence and can form part of the overall explanation to climate change. Measured over its life-cycle, sisal absorbs more carbon dioxide than it produces. During processing, it engenders mainly organic wastes and leaf residues that can be used to generate bio energy product from animal feed, fertilizer and ecological housing material and, at the end of its life cycle, sisal is 100 percent biodegradable. Natural and synthetic fibers are combined in the same matrix (unsaturated polyester) to make Sisal/Glass fiber hybrid composites and the compressive and impact properties of these hybrid composites were studied [11]. A significant improvement in compressive and impact properties of Sisal/Glass fiber hybrid composites has been found. The Chalk powder (additive) is also added to the resin (unsaturated polyester) in proportions of $1 \%, 2 \%, 3 \%$ by weight of resin respectively and Sisal/Glass fiber hybrid composites were prepared by using this resin to study the effect of Chalk powder on compressive and Impact properties of these hybrid composites. It is also observed that as the Chalk powder quantity increases, Compressive and impact properties decrease. It is observed that the compressive and impact strength of sisal/glass fiber hybrid component is higher than sisal fiber reinforced composite, but lower than the glass reinforced composite. The tensile stress, stain behavior of composites having $40 \%$ by weight fiber loading and performed one of the pioneering studies on the mechanical performance of treated oil palm fiber-reinforced composites were studied [12]. Short glass fiber reinforced polyester resin composites was developed with various combinations of natural (Jute) and synthetic (glass) fiber reinforcement. The variations of mechanical properties like tensile strength, flexural strength at different combinations of glass fibers and natural fibers has been studied and found that as synthetic fiber possesses high tensile properties, the tensile properties of composite increases with percentage increase in synthetic fiber [13]. Different chemical treatments [i.e., alkalized and mixed (alkalized+ salinized)] were used to improve the adhesion between the natural fibers (jute, ramie, sisal, and curauá) and the polymer matrix. [14]

This research was carried out to investigate the effect of chemical treatments at elevated temperature on the constituents of the Calotropis and sisal fiber and hence, the mechanical properties of long and transverse fiber reinforced polyester matrix composites. This is to be able to developed strong, durable and affordable building materials at low cost for replacement in most areas where wood is being used. 


\section{EXPERIMENTAL PROCEDURE}

\subsection{Materials}

Progressively, the ecosphere is comprehending that improved use must be made of expensive natural properties. Environmental cognizance has provoked many industries. Nevertheless, it is vibrant that the tide whisper towards environmentally-friendly engineering and product output is surging. In addition, a qualitative amendment has taken place in the method in which manufacturing industries are altering to consumers' environmental discernments. In the past, most exertions to capitalize on the green crusade focused on recycled products and environmentally friendly packaging resources. Today, industries progressively are looking straight at natural efforts in a more optimistic and pro-active method: Natural inputs are measured not only as theoretically valid components, but also as essentials that can subsidies to the premium-pricing of final products.

\subsubsection{Calotropis procera}

Calotropis procera, a desert plant, poisonous, is forming dominant element in sandy soil and salty wadi beds. It is a very common plant in the UAE. They are rich in fibers. Natural fibers have newly become striking to researchers, engineers and scientists as an alternate fortification for fiber reinforced polymer (FRP) composites. FRPs are extensively castoff in the aviation, naval and automotive industries for machineries that require a high ratio of strength to weight and durability. Calotropis gigentea can be named also as Calotropis procera. It is a swallow wort, Medium sized to large shrub; all parts of the plant comprise milky latex and soft white tomentum. Lilac colored flowers are found organized in an inflorescence, which is an umbellate cyme. The plant likewise has medicinal spigot. Its latex is used to eliminate spikes from the skin. The plant is resistant at least to zone 9 and scarcity forbearing (Figure 1).

\subsubsection{Sisal}

Figure 2, Sisal fiber is truly a package of muffled sub fibers. Their cell parapets are armored with spirally oriented cellulose in a hemi roughage and lignin environment. The composition of the external surface of the cell wall is a layer of ligneous material and waxy substances that bond the cell to its adjacent neighbors. In addition, cellulose is a hydrophilic in nature and this large amount of hydroxyl groups will give sisal fiber hydrophilic properties.

This will lead to a very poor interface between sisal and the hydrophobic matrix and very poor moisture absorption resistance. To make good use of sisal fiber reinforcement in composites, fiber surface treatment must be carried out to obtain an enhanced interface between the hydrophilic sisal fiber and hydrophobic polymer matrices. Modifications of interfaces between sisal and matrix can be done by different treatment of fibers.

\subsection{Pretreatment}

The treatment used is called mercerization as per ASTM 1965. In recent years, natural fibers have become commercial. Most fibers are produced in the form of multifilament bundles, usually called strands or ends in their untwisted forms and yarns when twisted, although definitions vary. Some fibers are produced as monofilaments, which generally have much larger diameters than strand filaments. Fiber measurements are categorized by their aspect ratio $1 / \mathrm{d}$ where 1 is the fiber length and $\mathrm{d}$ is the diameter. The strength progresses when the aspect ratio is great. Characteristic fiber diameters are from $10 \mathrm{~mm}$ to $150 \mathrm{~mm}$. 
Fibers frequently break because of surface imperfections. Making the diameter small lessens its surface area, which has scarcer flaws. Long fibers are favored because the ends of the fiber transmit less of the load. Thus the lengthier the fiber, the rarer the ends and the higher the load carrying size of the fibers.

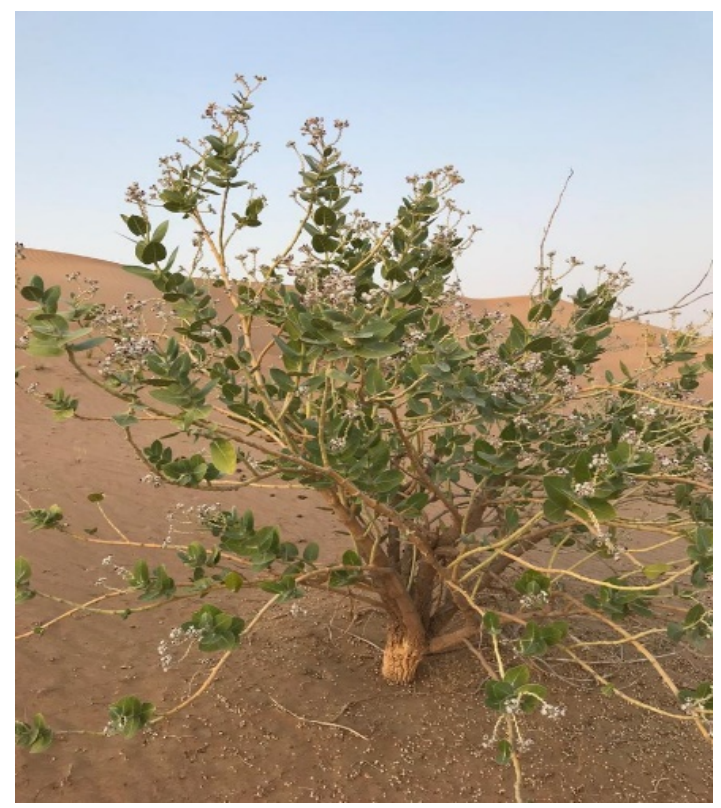

Figure 1: Calotropis Procera

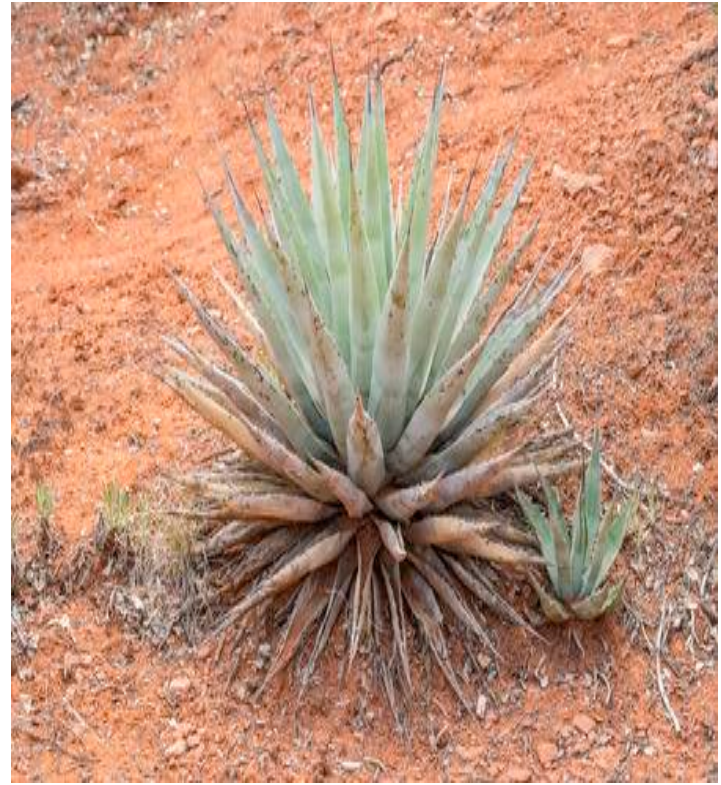

Figure 2: Agave (Sisal) Plant 
In this study, Calotropis and Sisal fibers were immersed in $5 \mathrm{wt}$ \% $\mathrm{NaOH}$ solutions for 24 to 48 hours, and the effects of the alkali treatments on the mechanical characteristics and interfacial adhesion of the fibers in a model Calotropis and Sisal fiber/epoxy composite system systematically evaluated. Then the fibers are washed with distilled water and left to dry at room temperature before being put in an oven for $15 \mathrm{~h}$ at $70^{\circ} \mathrm{C}$. Any smidgens of $\mathrm{NaOH}$, residual on the fiber surface, were deactivated with $2 \%$ sulfuric acid throughout $10 \mathrm{~min}$. The fibers were eroded over with distilled water until gaining a $\mathrm{pH}=7$. After chemical treatment, the fibers were dried at $60^{\circ} \mathrm{C}$ for 6 hours. Proper drying is important is for greater strength. This process is takes place depending upon the weather conditions. The weight loss after treatment was measured accordingly. Wet fiber leads to improper proportion and also weight. Calotropis gigentea and sisal fibers before and after mercerization are provided in Figure 3 and Figure 4.

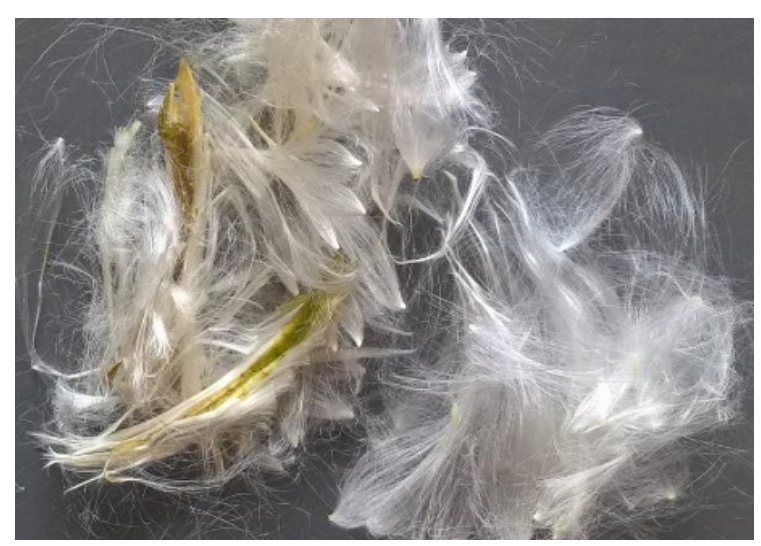

(a)

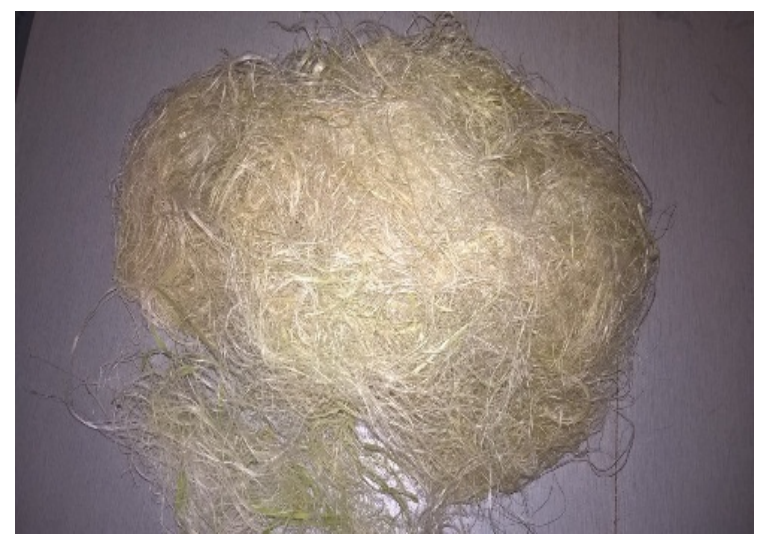

(b)

Figure 3: Calotropis gigentea fiber before and after mercerization 


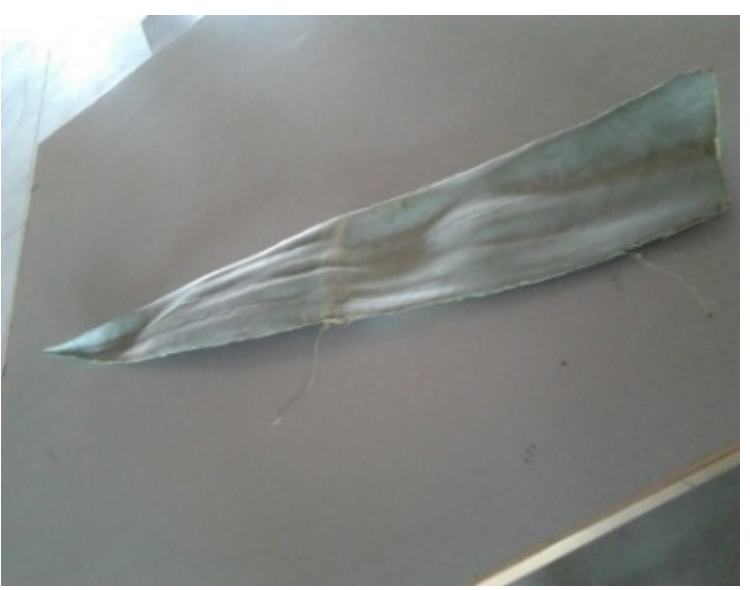

(a)

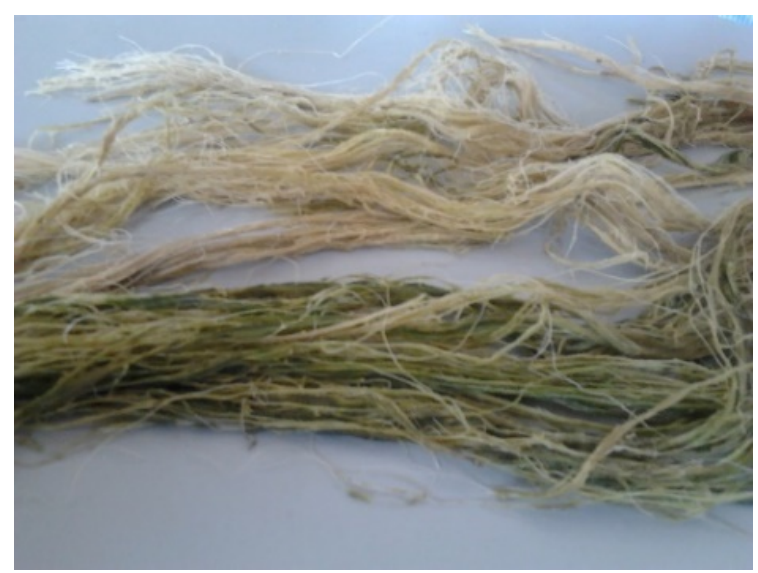

(b)

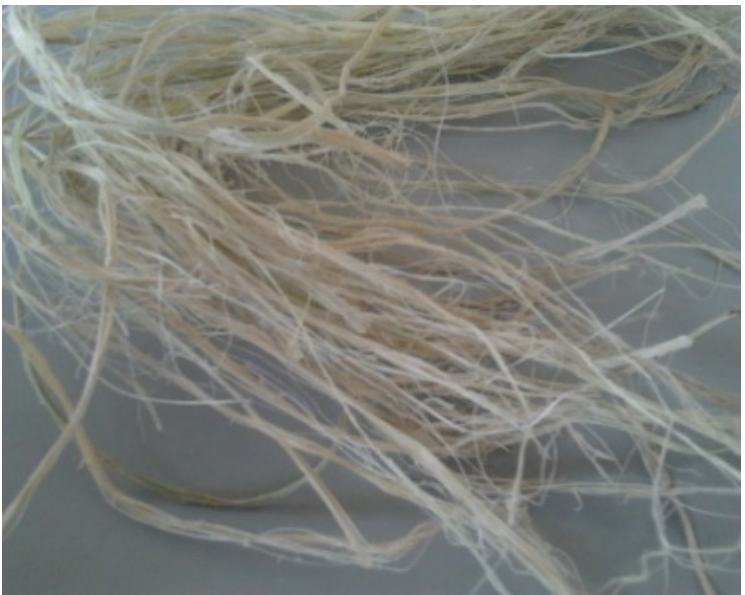

(c)

Figure 4: Sisal fiber before and after mercerization 


\subsection{Composite preparation}

In the present work, hand lay-up technique was used for making test specimens. Hybrid composites are designed and fabricated using raw Calotropis procera and sisal fiber/e-glass with varying fiber weight percent 5:0 to 5:3 weights by using hand layup method as per ASTM standard. In order to make the test specimens, the matrix system is poured into a mold made of mild steel, and air bubbles were removed carefully with a roller. The castings were allowed to cure for 24 hours at room temperature, post cured at $80^{\circ} \mathrm{C}$ for 1 hour and test specimens of the required size were cut out from the composite plate. Figure 5 shows the Calotropis and Sisal fiber reinforced hybrid composite plates.

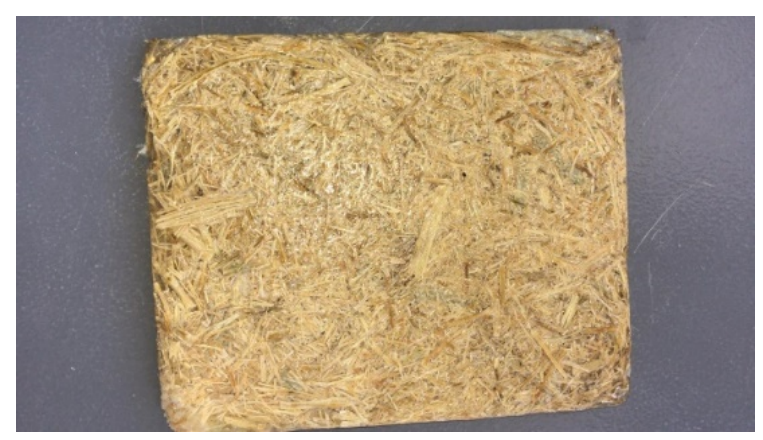

(a)

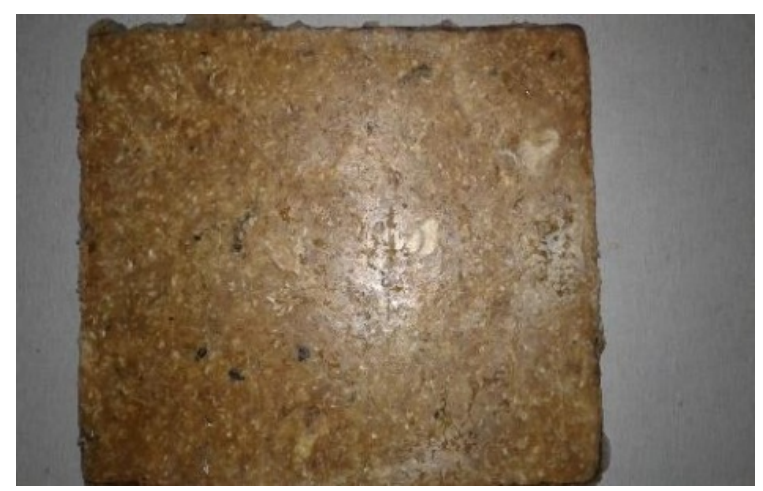

(b)

Figure 5: Calotropis and Sisal fiber reinforced hybrid composite sheets

\section{RESULTS AND DISCUSSION}

\subsection{Compression Strength}

From the various sections of the prepared composite, the specified dimension as $200 \mathrm{~mm} \times 40$ $\mathrm{mm} \times 12.5 \mathrm{~mm}$ were considered for the Compression test, which was conducted on a computerized universal testing machine with a capacity of 20 tones under the consideration of ASTM D638 standard. According to the literature evident, six specimens are tested and the mean value are tabulated, for which, all the six specimens are investigated with a crosshead speed of $2 \mathrm{~mm} / \mathrm{min}$ at room temperature $\left(25^{\circ} \mathrm{c}\right)$. Composite samples composition is given in Table 1. 
Table 1: Composite samples composition

\begin{tabular}{|c|c|c|c|c|}
\hline Sl. no. & Sample & Dimension & $\begin{array}{l}\text { Chemical } \\
\text { Treated }\end{array}$ & Composition \\
\hline \multicolumn{5}{|c|}{ Calotropis procera fiber } \\
\hline 1 & Sample 1 & $200 \times 40 \times 12.5$ & $\begin{array}{l}\text { Chemically } \\
\text { untreated }\end{array}$ & $\begin{array}{l}\text { Calotropis procera fiber }(40 \mathrm{wt} . \%) \\
\text { Epoxy }(50 \mathrm{wt.} \%) \\
\text { Glass fiber }(10 \mathrm{wt} . \%)\end{array}$ \\
\hline 2 & Sample 2 & $200 \times 45 \times 12.5$ & $\begin{array}{l}\text { Chemically } \\
\text { treated }\end{array}$ & $\begin{array}{l}\text { Calotropis procera fiber }(40 \mathrm{wt.} \%) \\
\text { Epoxy }(50 \mathrm{wt} . \%) \\
\text { Glass fiber }(10 \mathrm{wt} . \%)\end{array}$ \\
\hline \multicolumn{5}{|c|}{ Sisal fiber } \\
\hline 3 & Sample 3 & $120 \times 30 \times 3$ & $\begin{array}{l}\text { Chemically } \\
\text { untreated }\end{array}$ & $\begin{array}{l}\text { Sisal fiber }(40 \text { wt. } \%) \\
\text { Epoxy }(50 \text { wt. } \%) \\
\text { Glass fiber }(10 \text { wt. \%) }\end{array}$ \\
\hline 4 & Sample 4 & $120 \times 30 \times 3$ & $\begin{array}{l}\text { Chemically } \\
\text { treated }\end{array}$ & $\begin{array}{l}\text { Sisal fiber }(40 \text { wt. } \%) \\
\text { Epoxy }(50 \text { wt. } \%) \\
\text { Glass fiber }(10 \text { wt. \%) }\end{array}$ \\
\hline
\end{tabular}

\subsection{Flexural Strength}

The flexural strength of composite plate has been analyzed by experimental results. The test specimens with the dimension of $200 \mathrm{~mm} \times 45 \mathrm{~mm} \times 12 \mathrm{~mm}$ were used and the flexural test Flexural tests were performed using a three point bending set-up according to the ASTM D790 standard. The span length to the specimen thickness ratio is maintained at 16:1. At least five specimens were tested for each processing condition and the average reported.

Table 2: Brinell hardness number

\begin{tabular}{lccc}
\hline Sl. no. & Sample & Dimension & BHN \\
\hline 1 & & Calotropis procera Fiber & 79 \\
2 & Sample 1 & $200 \times 40 \times 12.5$ & 85.6 \\
\hline \multirow{3}{*}{ Sample 2 } & $200 \times 45 \times 12.5$ & 91.4 \\
4 & Sample 3 & $120 \times 30 \times 3$ \\
\hline
\end{tabular}

The evaluated (untreated and treated short fiber) composites as a function of fiber content in flexural, hardness and compression properties of fiber-epoxy composites are furnished in Table 2, 3 and 4.

Table 3: Evaluated Flexural properties of fiber-epoxy composites

\begin{tabular}{llllll}
\hline Sl. no. & Load (g) & \multicolumn{4}{c}{ Flexural strength(MPa) } \\
\cline { 3 - 6 } & & Sample 1 & Sample 2 & Sample 3 & Sample 4 \\
\hline 1 & 500 & 12 & 10 & 112 & 120 \\
2 & 1000 & 28 & 22 & 117 & 126 \\
\hline
\end{tabular}


Table 4: Compression test

\begin{tabular}{lll}
\hline Sl. no. & Sample & Maximum load (kN) \\
\hline 1 & Sample 1 & 300 \\
2 & Sample 2 & 500 \\
3 & Sample 3 & 400 \\
4 & Sample 4 & 189 \\
\hline
\end{tabular}

\subsection{Hardness test}

It is found that the hardness of the composite increases with the chemically treated fibers. In common, the fiber upsurges the modulus of compounds which in shot rises the hardness of fiber. Hardness is a task of relative fiber volume and modulus. Hardness value of $103.4 \mathrm{BHN}$ is obtained for chemically treated sisal epoxy specimen.

After 5 wt.\% NaOH treatment, Calotropis and Sisal fibers exhibited improved crystallinity, tensile strength and Young's modulus associated to untreated fibers, and similarly better interfacial shear strength with an epoxy. Sturdier alkali handlings destructively wedged fiber stiffness and appropriateness for composite applications. Results suggest that mild alkali treatments (e.g. 5 wt.\% $\mathrm{NaOH}$ for $2 \mathrm{~h}$ ) are highly beneficial for the manufacture of Calotropis and Sisal fiber-reinforced polymer composites.

\subsection{Morphology of Worn Surfaces}

Calotropis and Sisal fiber composite fracture surface morphologies the interfacial properties, such as fiber-matrix interaction, resin matrix fracture and lose, crack propagation and fiber pullout of fibers from the matrix, were observed using a VEGA3 TESCAN scanning electron microscope (SEM) operated at $10 \mathrm{kV}$. The SEM micrographs of the fracture surface (Chemically treated Calotropis procera fiber composite) as taken from the compression site (Figure 6 (a), (b)), where it can be seen that the de-bonding occurred in the vicinity of the glass and Calotropis fiber interface due to the kink. The gaps between the fiber and the matrix are largely appearing which leads to the de-bonding of the fiber from the matrix. The reason for this may again be attributed to the increase of a population of fiber defects and fiber ends with increased fiber content. The fiber defects (i.e. kinks) could act as a source of stress concentration in composites, as supported by the SEM micrograph (see Fig. 6-(b)). It is evident that flexural strength of the treated fiber composites was higher than that of the untreated fiber composites. Among all the treated fiber composites, alkali treated fiber reinforced composites had the highest flexural strength at all fiber contents. This could be attributed to the enhanced interfacial bonding. SEM micrographs of alkali-treated Calotropis and sisal fiber reinforced composites are shown in Figure 6 and 7.

The fiber breakage and matrix failure was observed. It is possible that treatment led to microfiber fibrillation. The surfaces become rather smoother as compared to that of untreated composites. In addition, this fibrillation could have augmented the actual surface area vacant for interaction with the matrix in the composites, as well as condensed the diameter of sisal fibers, thereby increasing their aspect ratio. This may bid improved fiber-matrix boundary adhesion and advances stress transfer. These will provide improvement in mechanical properties. 


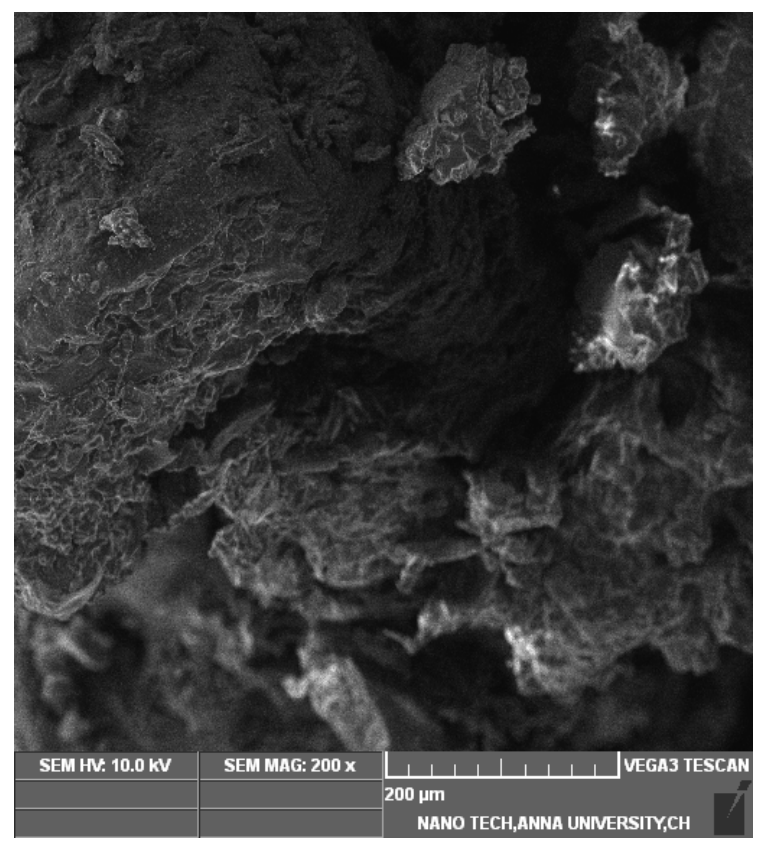

(a)

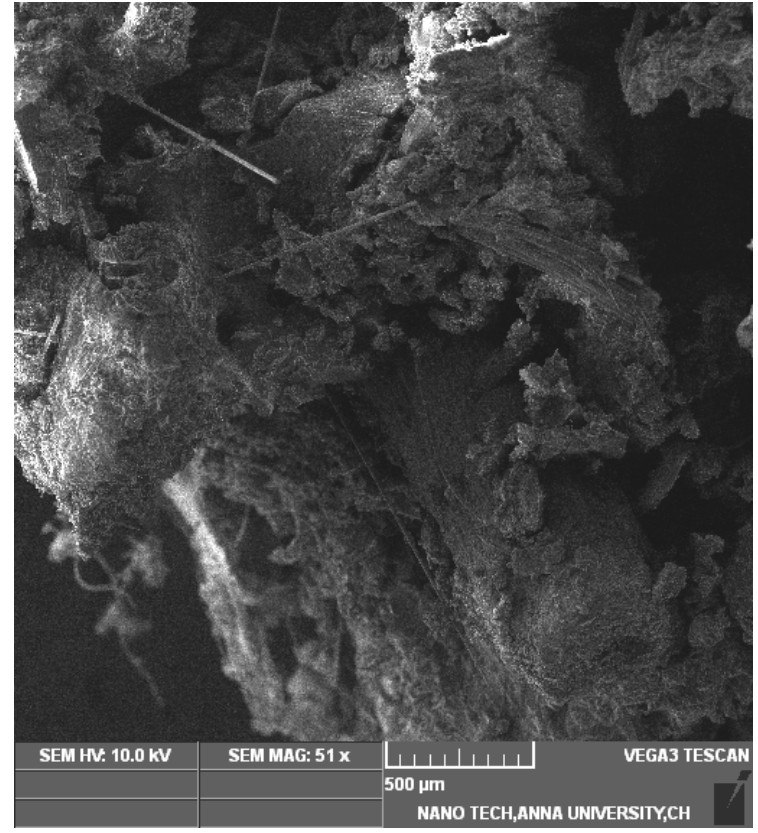

(b)

Figure 6 (a), (b): Fracture surface of chemically treated Calotropis fiber reinforced composites 


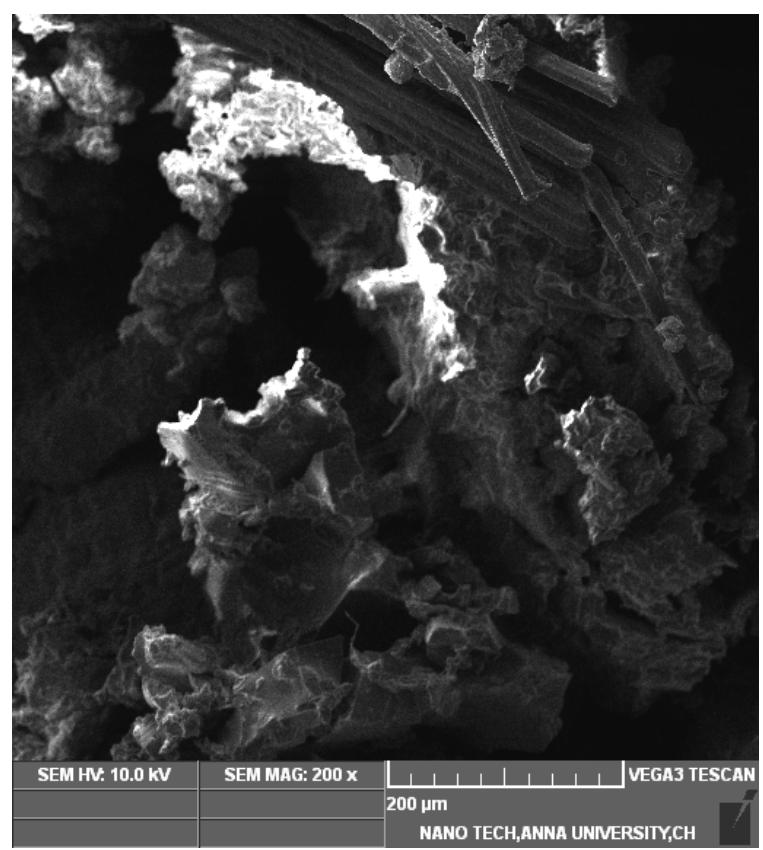

(a)

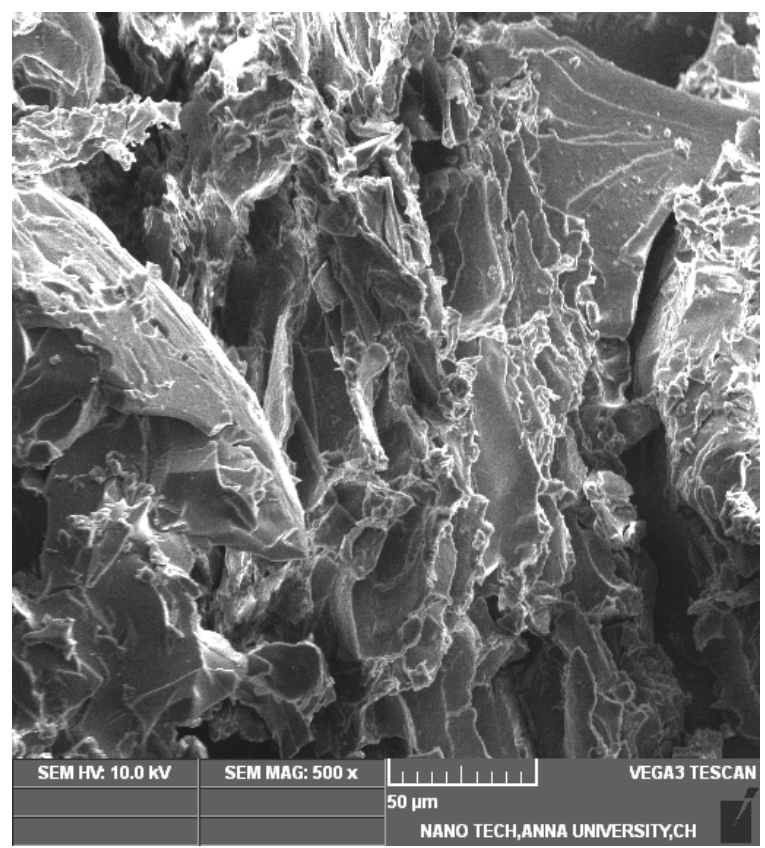

(b)

Figure 7 (a), (b): Fracture surfaces of chemically treated sisal fiber reinforced composites 
In this, the voids owing to fiber pull outs, fiber breakage, matrix breakage, and fiber-matrix de-bonding is detected. Because of bending load, the sisal fiber gets pulled out from the matrix due to poor adhesion resulting in the formation of voids. The cracks were formed near the void region due to continuous acting of bending load on the specimens. This crack starts propagating as far as the applied load acting on the specimens leading to total failure of the composites. By improving the compatibility between the sisal fiber and epoxy matrix, the flexural strength may be enhanced.

\section{CONCLUSION}

The Calotropis and Sisal fiber based epoxy matrix composites were manufactured successfully by using hand layup technique. The mechanical properties were premeditated before and after treating chemically. From the experimental outcomes, the subsequent inferences were attained:

- The proposed new composites provide high flexural strength which clearly shown that this natural fiber can be used instead of other natural fibers which is having low strength.

- Despite the fact this study produces a new natural fiber into the research but has some limitations, this study considered the weight proportion ratio of fiber upto composite by $60 \%$ each, hence, in future this can be extended with various proportions to find the optimum proportion ratio for effective results. The flexural, hardness and compression properties are evaluated for Calotropis and Sisal fiber-epoxy composites.

- The alkali treatment of fibers improves the quality of the fiber/matrix interface. Flexural test results showed that $\mathrm{NaOH}$ concentration used and time treatment have a significant effect on the mechanical properties of Calotropis and Sisal fiber composite fibers reinforced composites. An alkali treatment of fibers with $5 \% \mathrm{NaOH}$ over a period of 24 hours led to the improvement of flexural strength and modulus of about $60 \%$ and $62 \%$, respectively. They are utterly appropriate for usage as reinforcement in composites.

\section{REFERENCES}

[1] Aruna, M., Evaluation of mechanical properties of calotropis gigantea stem fiberreinforced composite material, 2016, International Conference on Current Research in Mechanical, Mechatronics, Robotics and Civil Engineering (ICMMRCE-16), Singapore.

[2] Mwaikambo, L.Y. and M.P. Ansell, Chemical modification of hemp, sisal, jute, and kapok fibers by alkalization. Journal of Applied Polymer Science, 2002. 84(12): p. 222234.

[3] Sunil V Chavan et al, Mechanical Properties of Jute fiber reinforced Polyester based composites under different environmental conditions. Advances in Polymer Science and Technology: An International Journal, 2016, 6(2), p.34-39.

[4] Sharma, A.P. and B.D. Tripathi, Assessment of atmospheric PAHs profile through calotropis gigantea R.Br. leaves in the vicinity of an Indian coal-fired power plant. 2009, Environmental monitoring and assessment, 146, p. 477-482.

[5] Karthik, T. and R. Murugan, Milkweed-A Potential Sustainable Natural Fibre Crop.2016, Environmental Footprints and Eco-design of Products and Processes, p.111-146. 
[6] Nazilla Tarabi et al, Design, construction and evaluation of fiber extracting machine from calotropis (milkweed) stems. 2015, Engineering in Agriculture, Environment and Food, 8(2), p. 88-94.

[7] Dilli Babu, G. et al, Tensile and wear behavior of calotropis gigentea fruit fiber reinforced polyester composites. 2014, Procedia Engineering, 97, p. 531-535.

[8] Chama Ajay Srinivas and G. Dilli Babu, Mechanical and machining characteristics of calotropis gigentea fruit fiber reinforced plastics. 2013, International Journal of Engineering Research \& Technology.

[9] Karthik, T. and P. Ganesan, Development of eco-friendly textile composites from calotropis gigentea bast fiber. 2012, International Journal of General Engineering and Technology, 1(1), p. 26-43.

[10] Alireza Ashori and Zaker Bahreini, Evaluation of Calotropis gigantea as a Promising Raw Material for Fiber-reinforced Composite. 2009, Journal of composite materials, 43(11), p. 1297-1304.

[11]Naga prasad naidu, V. et al, Compressive \& impact properties of sisal/glass fibre reinforced hybrid composites. 2011, International Journal of Fiber and Textile Research, 1(1), p.11-14.

[12] Sreekala M. S. et al, Oil palm fibre reinforced phenol formaldehyde composites: influence of fibre Surface modifications on the mechanical performance. 2000, Applied Composite Materials, 7, p. 295-329.

[13] Vemu. vara Prasad, Tensile and Flexural Properties of Glass fibre-reinforced Polyester hybrid composites. 2011, International Journal of Materials and Biomaterials Applications, 1(1), p.14-16.

[14]Neto, J. S. S. et al, Effect of chemical treatment on the thermal properties of hybrid natural fiber-reinforced composites. 2018, Journal of applied polymer science. 